\title{
Vida de prateleira de alface americana tratada com água ozonizada
}

\author{
Shelf life evaluation of the iceberg lettuce sanitized with ozone water

\begin{abstract}
Daniel Augusto Cavalcante ${ }^{\mathrm{I}}$ Bruno Ricardo de Castro Leite Júnior ${ }^{\mathrm{I}^{*}}$
\end{abstract} \\ Alline Artigiani Lima Tribst $^{\mathrm{I}}$ Marcelo Cristianini ${ }^{\mathrm{I}}$
}

\section{RESUMO}

\begin{abstract}
Este trabalho avaliou se a higienização de alface americana com água ozonizada, na concentração de $1,0 m g L^{-1}$ por 1, 2 ou 3 minutos, seria capaz de aumentar a vida útil do produto quando armazenado a $2{ }^{\circ} \mathrm{C}$. Foram avaliadas as populações de microrganismos aeróbios mesófilos, Enterobacteriaceae, bolores e leveduras, coliformes totais, coliformes termotolerantes e pesquisa de Salmonella sp. ao longo do tempo. Imediatamente após o processamento por 3 minutos, foram obtidas reduções decimais de 4,07; 3,36; 3,20; 2,18 e 2,18 de microrganismos aeróbios mesófilos, Enterobacteriaceae, bolores e leveduras, coliformes totais, coliformes termotolerantes, respectivamente. A presença de Salmonella sp. não foi observada em nenhuma das condições estudadas. Além do efeito na inativação inicial, o processamento com ozônio melhorou a estabilidade da alface durante a estocagem, aumentando o tempo para o início do crescimento microbiano (de zero para quatro dias) e reduzindo a taxa de crescimento dos microrganismos, especialmente quando a sanitização foi realizada por 3 minutos de contato. Os resultados demonstraram que a alface tratada com água ozonizada atendeu aos parâmetros da legislação durante o periodo avaliado, reduzindo a contaminação inicial das alfaces (que, sem tratamento, estavam microbiologicamente impróprias para consumo pela contagem de coliformes) $e$ mantendo essas contaminações em níveis aceitáveis por até 10 dias, sob refrigeração.
\end{abstract}

Palavras-chave: alface americana, água ozonizada, qualidade microbiológica, vida-de-prateleira.

\section{ABSTRACT}

This research studied the impact of Iceberg lettuce sanitation using ozonized water at 1.0mg $L^{-1}$ for 1, 2 and 3 minutes in the vegetable shelf-life at $2^{\circ} \mathrm{C}$. It was evaluated populations of aerobic mesophilic bacteria, EnterobacterIaceae, molds/ yeasts, total and thermtolerants coliforms, and Salmonella sp. Immediately after 3 minutes of sanitation, decimal reductions of 4.07 (aerobic mesophilic bacteria), 3.36 (EnterobacterIacea), 3.2 (molds/yeasts), 2.18 (total coliforms) and 2.18 (thermtolerants coliforms) were reached. Salmonella $s p$. was not founded at any evaluated condition. Additionally to the initial reduction, the ozonization improved the lettuce stability during its shelf-life, increasing the delay for microbial growth (from zero to four days) and reducing the microbial growth rate. It occurred especially when sanitation with ozone was carried for 3 minutes of contact. The results showed that the Iceberg lettuce sanitized with ozonated water meets the Brazilian law during the evaluated period, reducing lettuce initial load (that was initially unsafe due to high count of coliforms) and keeping this contamination acceptable for 10 days under refrigeration.

Key words: iceberg lettuce, ozonized water, microbiology quality, shelf life.

\section{INTRODUÇÃO}

O consumo de hortaliças e frutas tem aumentado em quantidade e variedade nos últimos anos. Nesse contexto, o mercado de minimamente processado é o que mais cresce por oferecer aos consumidores alimentos altamente nutritivos, convenientes, práticos e saudáveis, mantendo o frescor dos produtos in natura (NETO et al., 2012).

No Brasil, entre os vegetais folhosos, a alface da variedade americana (Lactuca sativa) é a mais consumida, com aproximadamente $40 \%$ do volume total comercializado (NETO et al., 2012). Devido à falta de higiene, desde a produção até o consumo, esses vegetais estão sendo associados com maior frequência em casos e surtos de doenças alimentares (RODRÍGUEZ-CATURLA et al., 2012).

'Departamento de Tecnologia de Alimentos, Faculdade de Engenharia de Alimentos, Universidade Estadual de Campinas (UNICAMP), Rua Monteiro Lobato, 80, Cidade Universitária, 13083-862, Campinas, SP, Brasil. E-mail: brunorclj@gmail.com. *Autor para correspondência. Recebido 15.07.13 Aprovado 26.03.15 Devolvido pelo autor 07.08.15 CR-2013-0952.R1 
Para os vegetais frescos em geral, a contaminação por microrganismos patogênicos pode ocorrer em diferentes fases (CRUZ et al., 2006). Na fase de produção agrícola, a contaminação pode ter origem no solo contaminado, na água de irrigação contaminada, no adubo orgânico, nos excrementos de animais, entre outros. Na colheita e no processamento, a contaminação pode ocorrer de forma cruzada entre os operadores, contêineres, equipamentos e durante o transporte (CRUZ et al., 2006). Já na fase de comercialização, os microrganismos presentes no vegetal embalado podem multiplicarse e, dependendo do tempo e da temperatura de conservação, podem atingir níveis que comprometem a qualidade do produto e/ou a integridade física do consumidor (GOPAL et al., 2010).

No caso da alface minimamente processada, as etapas do processamento que contribuem para o controle microbiológico são: seleção, eliminação das folhas externas e partes danificadas, pré-lavagem para remover as sujidades e terras aderidas às folhas, lavagem, sanitização, centrifugação, embalagem (em alguns casos, em atmosfera modificada ou a vácuo) e refrigeração (RODRÍGUEZ-CATURLA, 2012).

Segundo GOPAL et al. (2010), a maioria da produção de hortaliças folhosas e frutas é sanitizada com produto clorado (50 a 200ppm de cloro ativo). Porém, de acordo com os mesmos autores o tratamento com soluções cloradas em altas concentrações pode produzir, como subprodutos, substâncias prejudiciais à saúde como cloraminas e trihalometanos (GOPAL et al., 2010). Dessa forma, são necessários tratamentos alternativos mais efetivos que o cloro para redução ou eliminação de patógenos nestes vegetais sem comprometer a saúde dos consumidores.

Um método seguro regulamentado pelo Food and Drug Administration (FDA) para desinfecção de alimentos em unidades processadoras de alimentos, quando combinado com boas práticas de fabricação, é a utilização de água ozonizada (GUZEL-SEYDIM et al., 2004). O ozônio é um forte agente antimicrobiano, com alta reatividade e decomposição espontânea na água, em produtos não tóxicos (GUZEL-SEYDIM et al., 2004). Dois tipos de sistemas podem ser utilizados, o primeiro consiste em pulverizar o sanitizante no produto e o segundo consiste em mergulhar o alimento em uma solução ozonizada (SHARMA \& DEMIRCI, 2003). Dessa forma, esta tecnologia possui potencial para ser empregada na manutenção e/ou melhoria da qualidade e na segurança de produtos frescos, como vegetais minimamente processados, leite e queijos, assim como em câmaras frigoríficas (CAVALCANTE et al., 2013a; CAVALCANTE et al., 2013b; CAVALCANTE et al., 2014a; CAVALCANTE et al., 2014b).

Portanto, considerando o aumento atual no consumo de hortaliças e a alta carga de microrganismos prejudiciais à saúde pública nesses produtos, o objetivo deste trabalho foi avaliar o impacto da sanitização com água ozonizada na população de microrganismos naturalmente presentes em alface (imediatamente após o processamento) e o comportamento de crescimento destes microrganismos durante o armazenamento do vegetal por 10 dias a $2^{\circ} \mathrm{C}$, comparado com o crescimento deles em amostras lavadas com água sem adição de sanificante.

\section{MATERIAL E MÉTODOS}

O experimento foi realizado no laboratório da Fazenda da Aeronáutica de Pirassununga, SP. Todos os ensaios foram realizados em duplicata. As amostras de alface americana foram adquiridas no comércio de Santo André, SP, e transportadas sob refrigeração a $4^{\circ} \mathrm{C}$, até o laboratório da Fazenda da Aeronáutica de Pirassununga, SP. As alfaces tiveram folhas externas defeituosas e danificadas removidas, assim como os talos. Posteriormente, as amostras foram submetidas às etapas de separação e enxágue, recolhendo-se quantidade suficiente de alfaces para serem utilizadas nas próximas etapas.

\section{Gerador de Ozônio}

O equipamento utilizado na produção de ozônio foi fabricado pela empresa Panozon, constando de gerador de ozônio modelo PNZ 714, concentrador de oxigênio ( 90 a $95 \%$ de pureza), tanque de contato e um sistema de injeção com bomba para filtração. O ozônio gerado é borbulhado em um tanque para a obtenção da água ozonizada. $\mathrm{O}$ sistema possui também um tanque de gaseificação com a função de separar o ozônio que permaneceu na forma de gás e retirá-lo da tubulação, enviando-o para um circuito interno onde é destruído (reduzido a oxigênio). Após a ozonização, a água ozonizada foi transferida para uma cuba de aço inoxidável com capacidade de 50 litros (CAVALCANTE et al., 2013b; CAVALCANTE et al., 2014a).

Tratamento das amostras de alface com agua ozonizada Para etapa de sanitização com água ozonizada, as amostras foram dividas em três lotes contendo 21 amostras em cada lote, sendo mergulhadas em água ozonizada em uma 
concentração de $1,0 \mathrm{mg} \mathrm{L}^{-1}$ de ozônio, variando o tempo de imersão em 1, 2 e 3 minutos. Em seguida, as amostras foram embaladas em sacos plásticos de polietileno de baixa densidade (Mastervac, Brazil, model 200), contendo $150 \mathrm{~g}$ de produto em cada embalagem e armazenadas a $2^{\circ} \mathrm{C}$. A concentração de ozônio para cada processo foi controlada pelo teste colorimétrico (Brand $\mathrm{HACH}$, modelo OZ-2), capaz de avaliar a concentração de ozônio na faixa de 0-2,3mg L $\mathrm{m}^{-1}$ (CAVALCANTE et al., 2013b).

Para efeito comparativo, foram utilizadas amostras como controle (21 amostras para cada tempo de exposição), ou seja, mergulhadas somente em água da rede de abastecimento, seguindo as mesmas etapas anteriormente descritas.

\section{Análises microbiológicas}

Para o acompanhamento da vida de prateleira, foram realizadas análises microbiológicas em triplicatas de microrganismos aeróbios mesófilos, determinação do Número Mais Provável (NMP) de coliformes totais e coliformes termotolerantes, contagem de bolores e leveduras e Enterobacteriaceae e pesquisa de Salmonella sp. nos tempos controle (antes do tratamento com água ozonizada), zero (imediatamente após tratamento) e após 1, 2, 4, 6, 8 e 10 dias sob refrigeração a $2^{\circ} \mathrm{C}$, de acordo com o recomendado por DOWNES \& ITO (2001).

Para contagem de microrganismo aeróbios mesófilos, Enterobacteriaceae e bolores e leveduras, foram utilizados, respectivamente, Ágar Plate Count (PCA), Ágar Violet Red Bile Dextrose Ágar(VRBA) e Ágar Dextrose Acidificado (PDA). Para determinação do NMP de coliformes totais e termotolerantes, foram utilizados os Caldos Lauril Sulfato de Sódio (LST), Bile Verde Brilhante (VB) e Escherichia coli (EC). Para isolamento da Salmonella, foram utilizados o Caldo Seletivo Rappaport, o Ágar Verde Brilhante e o Ágar BPLS, seguindo a metodologia como recomendado por DOWNES \& ITO (2001).

\section{Análise estatística}

O número de reduções decimais (NRD) (equação 1) de cada amostra foi submetido à análise de variância ANOVA. Posteriormente, os dados foram submetidos ao teste de Tukey ao nível de $5 \%$ de significância para verificar a diferença entre as médias do NDR de cada tratamento. Os testes estatísticos foram realizados utilizando o software SAS (SAS, 2004). Os resultados foram expressos como média de NDR \pm desvio padrão das leituras.

Equação 1: NRD = log

$-\log$

\section{RESULTADOS E DISCUSSÃO}

A avaliação da contaminação inicial das alfaces indicou contagens de aeróbios mesófilos e enterobactérias da ordem de $10^{5} \mathrm{UFC} \mathrm{mL}^{-1}$, coliformes totais entre $10^{3}-10^{4} \mathrm{UFC} \mathrm{mL}^{-1}$, coliformes termotolerantes na ordem de $10^{2} \mathrm{UFCmL}^{-1}$ e bolores de leveduras na ordem $10^{4} \mathrm{UFC} \mathrm{mL}^{-1}$. Apesar de ser um nível de contaminação alto, este é esperado, devido ao fato de o cultivo tradicional de alface ser feito em canteiros de terra, onde, durante o seu desenvolvimento, o vegetal fica em contato com o solo, a adubação ser orgânica e a irrigação utilizando águas de rios ou lagos sem tratamento prévio. Além disso, o vegetal, após o corte, é intensivamente manipulado, aumentando os riscos de contaminação. Vale ressaltar que vegetais folhosos são normalmente produzidos no Brasil em pequenas unidades onde normalmente não se aplicam boas práticas agrícolas (BPA).

A tabela 1 apresenta os números de reduções decimais (NRD) para os microrganismos estudados após serem tratados com $1,0 \mathrm{mg} \mathrm{L}^{-1}$ de água ozonizada no tempo de contato de 1, 2 e 3 minutos. Os dados foram comparados com os obtidos pela imersão de alface em água da rede de abastecimento, de forma a excluir possíveis efeitos de lixiviação dos microrganismos pela água de lavagem, tornando possível a avaliação do real potencial de desinfecção do ozônio. Os resultados da tabela 1 demonstram que os tratamentos por 1, 2 e 3 minutos de imersão em água (amostras controle) não apresentaram diferença ente si $(\mathrm{P}>0,05)$ para todos os grupos de microrganismos avaliados. Além disso, não foram observados resultados significativos de redução de carga microbiológica (redução máxima de 0,34 ciclos logaritmos) para os mesmos grupos de microrganismos avaliados $(\mathrm{P}>0,05)$, possivelmente indicando que os microrganismos presentes na alface estavam aderidos à superfície do vegetal.

A higienização com água ozonizada, por outro lado, se mostrou efetiva na redução da contaminação de todos os microrganismos avaliados, sendo que, com o aumento do tempo de imersão, houve um aumento gradual e significativo da inativação microbiológica $(\mathrm{P}<0,05)$, indicando que o ozônio permaneceu ativo por todo o tempo de contato. Ao final de três minutos, foi observada total inativação de coliformes totais e termotolerantes, e mais de três ciclos de redução decimal para aeróbios mesófilos, enterobactérias e bolores e leveduras.

Como não foi detectada Salmonella em nenhuma amostra analisada e os coliformes termotolerantes foram reduzidos a valores inferiores a 
Tabela 1 - Número de reduções decimais (NDR) da contaminação inicial da alface americana, após tratamento com $1,0 \mathrm{mg} \mathrm{L}^{-1}$ de água ozonizada por 1, 2 e 3 minutos.

\begin{tabular}{lcccccc}
\hline \multirow{2}{*}{ Micro-organismo } & & & & & \\
& Ozônio & Água & Ozônio & Água & Ozônio \\
\hline Aeróbios mesófilos & $1,29^{\mathrm{c}} \pm 0,34$ & $0,05^{\mathrm{d}} \pm 0,03$ & $2,33^{\mathrm{b}} \pm 0,03$ & $0,14^{\mathrm{d}} \pm 0,02$ & $4,07^{\mathrm{a}} \pm 0,04$ & $0,25^{\mathrm{d}} \pm 0,06$ \\
Enterobacteriaceae & $1,66^{\mathrm{c}} \pm 0,16$ & $0,06^{\mathrm{d}} \pm 0,03$ & $3,19^{\mathrm{b}} \pm 0,24$ & $0,09^{\mathrm{d}} \pm 0,04$ & $3,36^{\mathrm{a}} \pm 0,19$ & $0,27^{\mathrm{d}} \pm 0,08$ \\
Coliformes totais & $1,55^{\mathrm{b}} \pm 0,13$ & $0,31^{\mathrm{c}} \pm 0,02$ & $2,06^{\mathrm{a}} \pm 0,03$ & $0,19^{\mathrm{c}} \pm 0,20$ & $2,18^{\mathrm{a}} \pm 0,05$ & $0,07^{\mathrm{c}} \pm 0,03$ \\
Coliformes termotolerantes & $1,84^{\mathrm{a}} \pm 0,02$ & $0,09^{\mathrm{b}} \pm 0,04$ & $1,88^{\mathrm{a}} \pm 0,04$ & $0,33^{\mathrm{b}} \pm 0,06$ & $2,18^{\mathrm{a}} \pm 0,04$ & $0,25^{\mathrm{b}} \pm 0,02$ \\
Bolores e Leveduras & $1,05^{\mathrm{c}} \pm 0,11$ & $0,06^{\mathrm{d}} \pm 0,02$ & $1,65^{\mathrm{b}} \pm 0,19$ & $0,09^{\mathrm{d}} \pm 0,01$ & $3,20^{\mathrm{a}} \pm 0,17$ & $0,34^{\mathrm{d}} \pm 0,03$ \\
\hline
\end{tabular}

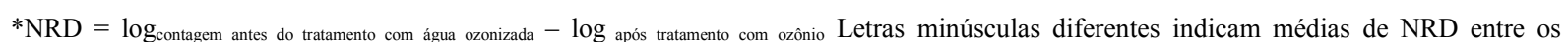
tratamentos estatisticamente diferentes pelo teste de Tukey em nível de $5 \%$ de probabilidade $(\mathrm{P}<0,05)$.

$3 \mathrm{NMP} \mathrm{g}^{-1}$ após 3 minutos de higienização com ozônio, na concentração de $1,0 \mathrm{mg} \mathrm{L}^{-1}$, pode-se concluir que o ozônio agiu como um eficiente sanificante, e o produto obtido após o tratamento passou a atender os requisitos estabelecidos pela RDC no 12 da ANVISA para alface in natura (BRASIL, 2001).

Resultados prévios (SINGH et al., 2002) compararam a efetividade de água ozonizada e dióxido de cloro na inativação de $\boldsymbol{E}$. coli $\mathrm{O} 157: \mathrm{H} 7$ em alfaces romanas e cenouras e observaram reduções similares às encontradas neste trabalho, de 3,75 ciclos para água ozonizada e 3,99 ciclos para o dióxido de cloro. Assim, esses dados sugerem que a higienização com água ozonizada pode substituir o processo de cloração, que apresenta como inconvenientes a formação de cloraminas e trihalometanos, que podem ser tóxicos para a saúde humana, dependendo da concentração. Em outro estudo, realizado por CAVALCANTE et al. (2014a), foi verificado que a água ozonizada isoladamente na concentração de $1,0 \mathrm{mg} \mathrm{L}^{-1}$ a 1 e 3 minutos foi capaz de inativar 6,6 e mais de 8 ciclos de E. coli O157:H7 e 5,3 e 5,8 ciclos de Bacillus subtilis, respectivamente. Esses resultados demonstram que, possivelmente, a matriz alimentar exerça efeito protetivo a estes microrganismos.

As figuras 1 e 2 mostram o efeito da lavagem das alfaces por imersão por 1, 2 ou 3 minutos em água de abastecimento público e em água ozonizada na concentração de $1,0 \mathrm{mg} \mathrm{L}^{-1}$. Após a lavagem, foi acompanhado o desenvolvimento de microrganismos aeróbios mesófilos (Figura 1A), enterobactérias (Figura 1B), bolores e leveduras (Figura 1C) e coliformes totais (Figura 2A) e termotolerantes (Figura 2B) durante 10 dias de estocagem, tempo comum esperado entre produção e consumo.

Os resultados obtidos durante a estocagem dos vegetais indicaram que aqueles que foram apenas lavados com água da rede de abastecimento não tiveram redução em nenhum dos grupos de microrganismos avaliados. Durante a estocagem a $2^{\circ} \mathrm{C}$, houve um aumento de cerca de dois ciclos logarítmico nas contagens de microrganismos mesófilos aeróbios, coliformes totais, coliformes termotolerantes e bolores e leveduras e de um ciclo na contagem de enterobactérias, indicando que, mesmo a baixas temperaturas, os microrganismos foram capazes de se desenvolver lentamente na alface. A avaliação das curvas de crescimento obtidas demonstra que este se iniciou desde o início da estocagem, com taxa constante ao longo do tempo.

As alfaces submetidas à higienização com ozônio apresentaram comportamentos diferentes em função do tipo de microrganismo avaliado e também da concentração de ozônio utilizada. Para os microrganismos mesófilos aeróbios, foi observado que o tratamento por um minuto foi capaz de controlar o crescimento apenas por seis dias de estocagem ( $<1$ ciclo de crescimento), enquanto que, quando a higienização foi realizada por 2 ou 3 minutos, houve menor desenvolvimento dos microrganismos, com aumento inferior a um ciclo após 10 dias de armazenamento.

$\mathrm{O}$ efeito em enterobactérias indicou que apenas quando a alface foi higienizada com ozônio por 3 minutos a contagem microbiana se manteve inalterada (aumento inferior a 0,5 ciclo) pelos 10 dias de estocagem. Para as amostras tratadas por $1 \mathrm{e}$ 2 minutos, a contaminação se manteve estável por 6 dias e, em seguida, as enterobactérias apresentaram um crescimento exponencial, atingindo uma contagem de 2 ciclos logaritmos superior após 10 dias de estocagem. Novamente, os resultados obtidos para bolores e leveduras indicaram que o processo foi capaz de controlar o crescimento de microrganismos por 4 dias de estocagem, seguido de crescimento com aumento da contagem em 2 ciclos ao final da 

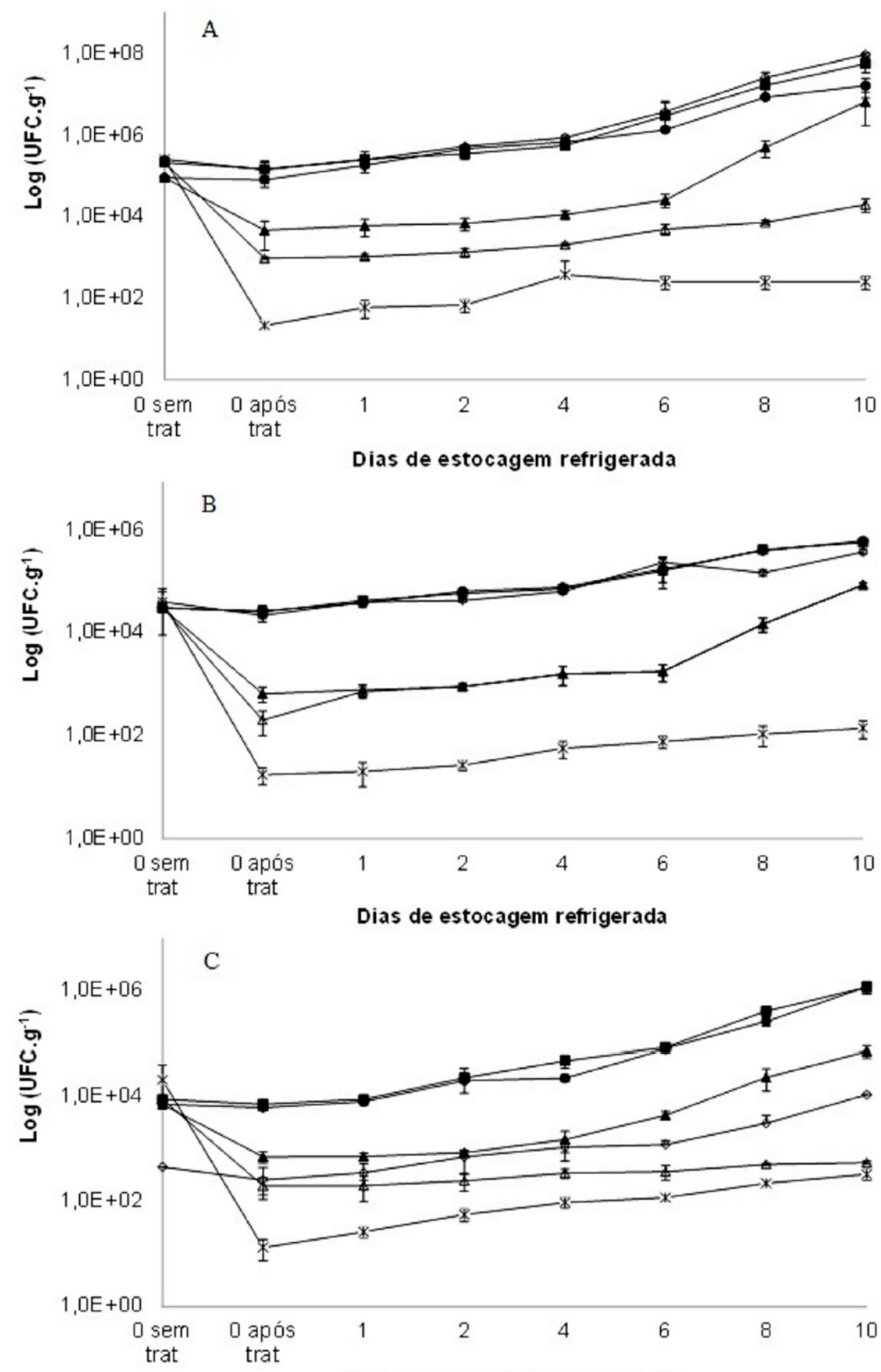

Dias de estocagem refrigerada

-Ozônio - 1ppm/1min $\neg$ Ozônio - 1ppm/2min -*-Ozônio - 1ppm/3min

$\multimap$ Água - $1 \mathrm{ppm} / 1 \mathrm{~m}$ in $\rightarrow$ Água - $1 \mathrm{ppm} / 2 \mathrm{~min} \rightarrow$ Água - $1 \mathrm{ppm} / 3 \mathrm{~min}$

Figura 1 - Crescimento microbiano de aeróbios mesófilos (A), Enterobacteriaceae (B) e Bolores e Leveduras (C) em alface americana antes e após tratamento com água ozonizada na concentração de $1 \mathrm{mg} \mathrm{L}^{-1}$ por 1,2 e 3 minutos. 


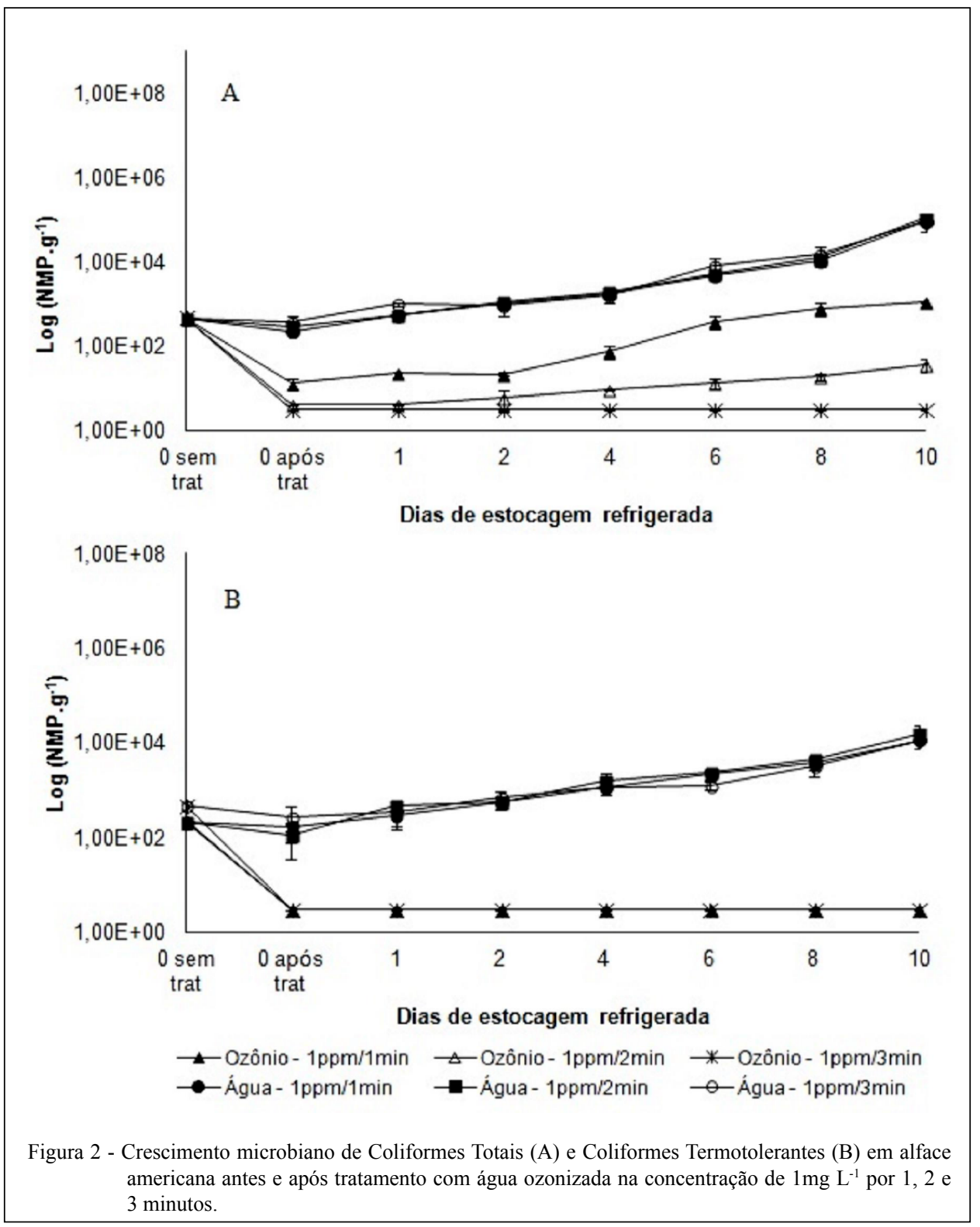

estocagem, quando o tempo de contato foi de um minuto e que, com tempos de contato de 2 e 3 minutos, um comportamento similar foi observado, com aumento de aproximadamente um ciclo logarítmico após os 10 dias de estocagem.

Já para os coliformes totais, o tempo de contato com a água ozonizada afetou o crescimento dos microrganismos durante a estocagem, sendo que, quando o tempo de higienização foi de apenas um minuto, as contagens permaneceram estáveis apenas nos dois primeiros dias e, em seguida, apresentaram um crescimento lento e gradual, com aumento de 2 ciclos após os 10 dias de estocagem. Quando o tempo de higienização foi dois minutos, a contagem também se manteve estável nos dois primeiros dias e, em seguida, apresentou um crescimento bem lento, aumentando apenas um ciclo ao final dos 10 dias de estocagem. Por outro lado, para o tempo de contato de 3 minutos, não foi observado aumento na contagem do microrganismo durante o período de estocagem. Para os coliformes termotolerantes, a completa inativação da carga microbiana inicial causada pelo efeito do ozônio, independentemente do tempo de tratamento, foi mantida durante o período de estocagem. Assim, concluiu-se que este grupo de microrganismo foi o mais sensível à ação do ozônio como sanificante. 
A avaliação das curvas de crescimento mostrou que o processo, além de promover uma redução da carga inicial de cada classe de microrganismos estudado, também causa um retardo no crescimento dos microrganismos sobreviventes, possivelmente por um efeito de injúria subletal sobre eles. Esse efeito foi diferente entre os microrganismos avaliados, sendo que, para os mais susceptíveis (coliformes termotolerantes), não foi observado crescimento mesmo após tratamento por um minuto com água ozonizada, enquanto que, para os mais resistentes, o tempo de retardo de crescimento foi proporcional ao tempo de lavagem com água ozonizada.

Considerando-se os requisitos da legislação para alface (RDC no 12 da ANVISA), que prevê apenas ausência de Salmonella e concentração de coliformes termotolerantes inferiores a $3 \mathrm{NMP} \mathrm{g}^{-1}$, pode-se afirmar que a concentração de ozônio de $1,0 \mathrm{mg} \mathrm{L}^{-1}$ por 1,2 ou 3 minutos de contato atendem a legislação brasileira (BRASIL, 2001) por até 10 dias de armazenamento. Porém é importante ressaltar que a presença de deterioradores pode afetar as características sensoriais da alface. Portanto, pode-se afirmar que o tratamento com ozônio por 3 minutos seja ideal, de forma a manter baixa a contagem de todos os grupos de microrganismos avaliados.

Segundo RODRÍGUEZ-CATURLA et al. (2012), a perda do valor comercial de produtos frescos ocorre quando a contagem de microrganismos deterioradores atinge um nível populacional de $10^{6}$ a $10^{8} \mathrm{UFC} \mathrm{g}^{-1}$, o que geralmente não excede 5 a 7 dias sob temperaturas variando de 5 a $7^{\circ} \mathrm{C}$. Esse nível de contagens foi observado apenas para amostras de alface lavadas com água sem adição de ozônio após 6 dias de estocagem e, para as amostras lavadas com água ozonizada com 1 minuto de contato, após 10 dias de estocagem a $2^{\circ} \mathrm{C}$. Esses dados comprovam o ozônio na concentração de $1,0 \mathrm{mg} \mathrm{L}^{-1}$ como um interessante agente sanificante e que melhores resultados são obtidos com tempo de contato entre produto e água ozonizada de 3 minutos. Além disso, a tecnologia de ozônio pode ser produzida a partir de um gerador utilizando a própria água de abastecimento, assim, uma vez obtido o equipamento, a geração do ozônio é de baixo custo. Portanto, este estudo mostrou que a água ozonizada pode ser uma boa alternativa para melhorar a qualidade microbiológica de produtos frescos. No entanto, é importante que estudos futuros avaliem diferentes tipos de produtos hortícolas e de microrganismo patogênicos para ampliação dos conhecimentos deste importante sanificante.

\section{CONCLUSÃO}

A água ozonizada na concentração de $1,0 \mathrm{mg} \mathrm{L} \mathrm{L}^{-1}$ apresentou uma ação efetiva na desinfecção de alface americana, sendo que esta inativação aumentou proporcionalmente em função do tempo de contato das alfaces com a água ozonizada, medido por até três minutos. Além disso, as amostras submetidas à ozonização apresentaram retardo do crescimento dos microrganismos sobreviventes durante a estocagem, sendo que a utilização da água ozonizada na concentração de $1,0 \mathrm{mg} \mathrm{L}^{-1}$ por 3 minutos foi capaz de promover a adequação da alface durante 10 dias de estocagem a $2^{\circ} \mathrm{C}$, atendendo os parâmetros microbiológicos preconizados pela legislação vigente. Quanto ao efeito sobre a Salmonella, nada pode ser afirmado, pois o microrganismo não foi isolado do controle. De qualquer forma, é possível concluir que os resultados obtidos neste estudo ampliam o conhecimento sobre os efeitos do ozônio como sanificante e destacam a aplicação desta metodologia como um processo adicional para redução da carga microbiana em alface, especialmente considerando-se as dificuldades ainda existentes quanto ao atendimento as Boas Práticas na Agricultura brasileira.

\section{COMITÊ DE ÉTICA E BIOSSEGURANÇA}

O produto desta pesquisa não envolveu análise sensorial com participação de seres humanos, dispensando, portanto, a submissão do projeto ao comitê de ética em pesquisa com seres humanos. Da mesma forma, como não houve manipulação de animais vivos neste projeto, não houve submissão ao comitê de ética em pesquisa envolvendo animais.

\section{REFERÊNCIAS}

BRASIL. Agência Nacional de Vigilância Sanitária. Resolução RDC n.12, de 2 de janeiro de 2001. Regulamento técnico sobre os padrões microbiológicos para alimentos. Diário Oficial da União, Brasília, DF, 10 jan, 2001

CAVALCANTE, D.A. et al. Improvement of the raw milk microbiological quality by ozone treatment. International Food Research Journal, v.20, n.4, p.2017-2021, 2013a. Disponível em: $\quad<$ http://www.ifrj.upm.edu.my/20\%20(04)\%202013/72\%20 IFRJ\%2020\%20(04)\%202013\%20Tribst\%20(107).pdf>. Acesso em: 24 jun. 2014

CAVAlCANTE, D.A. et al. Microbiological quality of Minas Frescal cheese treated with ozonated water. International Food Research Journal, v.20, n.5, p.2911-2915, 2013b. Disponível em: $\quad<$ http://www.ifrj.upm.edu.my/20\%20(05)\%202013/50\%20 IFRJ\%2020\%20(05)\%202013\%20Tribst\%20100.pdf>. Acesso em: 24 set. 2014 .

CAVALCANTE, D.A. et al. Inativação de Escherichia coli O157:H7 e Bacillus subtilis por água ozonizada. Boletim do Centro de Pesquisa e Processamento de Alimentos, v.32, p.105- 
112, 2014a. Disponível em: <http://ojs.c3sl.ufpr.br/ojs/index.php/ alimentos/article/view/36931>. Acesso em: 24 jul. 2014. doi: 10.5380/cep.v32i1.36931.

CAVALCANTE, D.A. et al. Uso de ozônio gasoso na sanitização de câmaras frigoríficas. Revista do Instituto de Laticínios Cândido Tostes, v.69, p.121-128, 2014b. Disponível em: <http:// www.revistadoilct.com.br/rilct/article/view/280>. Acesso em: 24 set. 2014. doi: 10.14295/2238-6416.v69i2.280.

CRUZ, A.G. et al. Good agricultural practices in a Brazilian produce plant. Food Control, v.17, p.781-788, 2006. Disponível em: <http://www.sciencedirect.com/science/article/pii/ S0956713505001210>. Acesso em: 24 jul. 2014. doi: 10.1016/j. foodcont.2005.05.002.

DOWNES, F.P.; ITO, K. Compendium of methods for the microbiological examination of foods. 4.ed. Washington, D.C.: APHA/Technical Committee on Microbiological for Foods, 2001. 676p

GOPAL, A. et al. Alternative disinfection techniques to extend the shelf life of minimally processed iceberg lettuce. Food Microbiology, v.27, p.210-219, 2010. Disponível em: <http://www sciencedirect.com/science/article/pii/S0740002009002329?np=y>. Acesso em: 11 mar. 2014. doi: 10.1016/j.fm.2009.10.006.

GUZEL-SEYDIM, Z.B. et al. Use of ozone in the food industry. Lebensmittel-Wissenschaft und Technologie - LWT, v.37, p.453-460, 2004. Disponível em: <http://www.sciencedirect.com/ science/article/pii/S0023643803002068>. Acesso em: 21 nov. 2014. doi: 10.1016/j.lwt.2003.10.014
NETO, N.J.G. et al. Bacterial counts and the occurrence of parasites in lettuce (Lactuca sativa) from different cropping systems in Brazil. Food Control, v.28, p.47-51, 2012. Disponível em: < http://www.sciencedirect.com/science/article/pii/ S095671351200206X>. Acesso em: 10 set. 2014. doi: 10.1016/j. foodcont.2012.04.033

RODRÍGUEZ-CATURLA, M.Y. et al. Development of a risk-based methodology for estimating survival and growth of enteropathogenic Escherichia coli on iceberg-lettuce exposed at short-term storage in foodservice centers. Journal of Microbiological Methods, v.90, p.273-279, 2012. Disponível em: < http://www.sciencedirect. com/science/article/pii/S0167701212002102?np=y>. Acesso em: 16 abr. 2014. doi: 10.1016/j.mimet.2012.05.021.

SAS INSTITUTE 9.1 User.sguide. Carey: SAS Institute, 2004. 1040p.

SHARMA, R.R.; DEMIRCI, A. Application of ozone for inactivation of Escherichia coli $0157: \mathrm{H} 7$ on inoculated alfafa sprouts. Journal of Food Processing Preservation, v.27, p.51-64, 2003. Disponível em: <http://onlinelibrary.wiley.com/ doi/10.1111/j.1745-4549.2003.tb00500.x/abstract>. Acesso em: 20 out. 2014. doi: 10.1111/j.1745-4549.2003.tb00500.x.

SINGH, N. et al. Efficacy of chlorine dioxide, ozone, and thyme essential oil or a sequential washing in killing Escherichia coli $\mathrm{O} 157: \mathrm{H} 7$ on Lettuce and baby carrots. LebensmittelWissenschaft und Technologie - LWT, v.35, p.720-729, 2002. Disponível em: <http://www.sciencedirect.com/science/article/pii/ S0023643802909333>. Acesso em: 21 fev. 2014. doi: 10.1006/ fstl.2002.0933. 